\title{
ENDOSCOPIC SUBMUCOSAL DISSECTION FOR THE TREATMENT OF EARLY ESOPHAGEAL AND GASTRIC CANCER - INITIAL EXPERIENCE OF A WESTERN CENTER
}

\author{
Dalton Marques Chaves, ${ }^{\mathrm{I}}$ Fauze Maluf Filho, ${ }^{\mathrm{II}}$ Eduardo G. H. de Moura, ${ }^{\mathrm{I}}$ Marcos Eduardo Lera dos Santos, ${ }^{\mathrm{I}}$ Livia Ronise

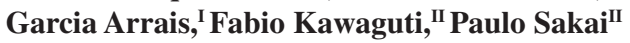

doi: $10.1590 / \mathbf{S 1 8 0 7 - 5 9 3 2 2 0 1 0 0 0 0 4 0 0 0 0 5}$

Chaves DM, Maluf-Filho F, de Moura EGH, dos Santos MEL, Arrais LRG, Kawaguti F et al. Endoscopic submucosal dissection for the treatment of early esophageal and gastric cancer - initial experience of a western center. Clinics. 2010;65(4):377-82.

BACKGROUND: Endoscopic submucosal dissection is a new Japanese technique characterized by en-bloc resection of the entire lesion irrespective of size, with lower local recurrence when compared to endoscopic mucosal resection.

OBJECTIVE: To evaluate the feasibility, early results and complications of the endoscopic submucosal dissection technique for treating early gastric and esophageal cancer at the Endoscopic Unit of Clinics Hospital and Cancer Institute of the São Paulo University. MATERIALS AND METHODS: Twenty patients underwent endoscopic resection using the endoscopic submucosal dissection technique for early gastric or esophageal cancer. The patients were evaluated prospectively as to the executability of the technique, the short-term results of the procedure and complications.

RESULTS: Sixteen gastric adenocarcinoma lesions and six esophageal squamous carcinoma lesions were resected. In the stomach, the mean diameter of the lesions was $16.2 \mathrm{~mm}(0.6-3.5 \mathrm{~mm})$. Eight lesions were type IIa + IIc, four were type IIa and four IIc, with thirteen being well differentiated and three undifferentiated. Regarding the degree of invasion, five were M2, seven were M3, two were Sm1 and one was Sm2. The mean duration of the procedures was 85 min (20-160 min). In the esophagus, all of the lesions were type IIb, with a mean diameter of $17.8 \mathrm{~mm}(6-30 \mathrm{~mm})$. Regarding the degree of invasion, three were M1, one was M2, one was M3 and one was Sm1. All had free lateral and deep margins. The mean time of the procedure was $78 \mathrm{~min}$ (20-150 min). CONCLUSION: The endoscopic submucosal dissection technique was feasible in our service with a high success rate.

KEYWORDS: Endoscopic mucosal; resection; endoscopic submucosal dissection; early gastric cancer; early esophageal cancer; endoscopy.

\section{INTRODUCTION}

Upper gastrointestinal (GI) endoscopy has been valuable for the diagnosis, staging and treatment of early-stage GI neoplasias. Lesions confined to the mucosa throughout the GI tract are susceptible to endoscopic resection, allowing for minimally invasive and curative treatment.

The resection of neoplastic tissue through endoscopic techniques, known as endoscopic mucosal resection (EMR),

I Gastrointestinal Endoscopy Unit, Hospital das Clínicas da Faculdade de Medicina da Universidade de São Paulo - São Paulo/SP, Brazil.

II Cancer Institute of São Paulo - São Paulo/SP, Brazil.

Tel. : 55113069.6221

Email: dalton.chaves@fleury.com.br

Received for publication on November 09, 2009

First review completed on December 01, 2009

Accepted for publication on January 19, 2010 allows for histological analysis of the resected specimen, thereby allowing diagnostic confirmation and determination of the degree of invasion depth into the wall of the organ. This is relevant for determining whether the endoscopic resection was curative.

Currently, there are several EMR methods that may be divided according to the technique of mucosal capture into: traction (strip-biopsy or lift-and-cut); suction (cap and elastic band ligation); and compression (monofilament snare).

Endoscopic submucosal resection (ESD) is a new Japanese technique that involves en-bloc resection of the entire lesion irrespective of size, allowing for a detailed analysis of the resected margins and depth of invasion and producing a lower local recurrence when compared to EMR techniques (1). Most of the relevant series on 
Table 1 - Indication criteria adopted for gastric cancer endoscopic submucosal resection.

\begin{tabular}{ll}
\hline INTRAMUCOSAL CANCER & SUBMUCOSAL CANCER \\
\hline Differentiated adenocarcinoma & - Superficial submucosal invasion, $<500 \mu \mathrm{m}(\mathrm{Sm} 1)$ \\
- No lymphatic-vascular invasion & - Differentiated adenocarcinoma \\
- Irrespective of tumor size without ulcer findings & - No lymphatic-vascular invasion \\
- Tumor less than $3 \mathrm{~cm}$ in size with ulcer findings & - Tumor less than $3 \mathrm{~cm}$ in size \\
\hline Undifferentiated adenocarcinoma & \\
- No lymphatic-vascular invasion & \\
- No ulcer findings & \\
- Tumor less than $2 \mathrm{~cm}$ in size & \\
\hline
\end{tabular}

ESD describe the experience of eastern centers, where it is already incorporated into routine practice. Based on the eastern experience, it is clear that ESD is a complex and time-consuming technique, which are factors that might hinder the diffusion of this new modality of endoscopic treatment.

The aim of this study is to report the feasibility of ESD in our institution, specifically addressing the initial results and the technique employed.

\section{PATIENTS AND METHODS}

Between March 2007 and January 2009, 20 patients with early stage gastric or esophageal cancer were prospectively included in the present study. They were treated by two senior physicians using the ESD technique, which was performed in the Gastrointestinal Endoscopy Unit of the Clinics Hospital and the Cancer Institute of the São Paulo University. The procedures were performed with the consent of the patients after they were informed of the risks and benefits of the method.

Before the procedure was developed, all of the diagnoses were done through endoscopic biopsies, and staging was done by echo-endoscopy with a $12 \mathrm{MHz}$ miniprobe, except in cases in which endoscopy was highly suggestive of an early lesion.

Using a standard video endoscope (Olympus GIF-Q140 or GIF-Q160; Olympus, Tokyo, Japan) with $2 \%$ Lugol's solution for the esophagus and $0.4 \%$ Indigocarmin for the stomach, the lesions were classified as Japanese endoscopic superficial cancer, and we observed the location and superficial extent of the lesions.

The indication and cure criteria adopted for ESD in the stomach were the same as those published by Godota et al. ${ }^{1}$ (Table1).

The indications and cure criteria for ESD in the esophagus have also been previously described ${ }^{(2,3,4)}$ (Table 2).
Table 2 - Indication criteria adopted for esophageal cancer endoscopic submucosal resection

\footnotetext{
- Endoscopic signs of early lesions or echo-endoscopic examination confirming tumor limited to the mucosa or up to the superficial submucosa $(\mathrm{Sm} 1)$.

- Histological confirmation of squamous cell carcinoma or high-grade intraepithelial neoplasia restricted to the mucosa (M1 and M2).

- Lesions with M3 or Sm1 invasion without lymphatic and vascular involvement, no larger superficial size $(<2.5 \mathrm{~mm})$.

- No signs of lymph node metastases.
}

\section{Technical method of ESD employed}

The ESD was done using a needle knife with a ceramic ball in its tip, known as an insulation-tipped diathermic knife (IT-knife, Olympus Inc. São Paulo, Brazil).

The technique employed had the following basic stages: marking of the periphery of the lesion with a conventional needle knife set at $20 \mathrm{~W}$ coagulation mode (ICC200, Erbe, Tubingen, Germany); injection of $250 \mathrm{ml}$ of saline solution or Manitol $(10 \%)+1 \mathrm{ml}$ of epinephrine $(1: 1000)+2 \mathrm{~mL}$ of $0.5 \%$ indigo carmine dye into the submucosa; generation of small incisions in the mucosa at the periphery of the lesion at four cardinal points with the conventional needle knife set at $80 \mathrm{~W}$ endocut mode with effect 3 (ICC200, Erbe, Tubingen, Germany); circumferential mucosal cutting with the IT knife gathering the four openings performed with the needle knife; and submucosal dissection of the entire lesion with the IT knife (re 1).

Prophylactic antibiotic IV was administered in all patients.

The time of the procedure was recorded in all cases from the point of marking the periphery of the lesion to the complete resection of the lesion.

\section{Post EDS histological analyses}

The resected specimens were retrieved, stretched and 
pinned onto a Styrofoam plate, and fixed in $10 \%$ formalin. Histological evaluation was performed using Japanese criteria, and the following points were analyzed: degree of differentiation, depth of invasion per the Japanese classification of early-stage cancer, and lateral margin involvement by the lesion.

The resection was considered curative if it met the criteria of resection presented in Tables 1 and 2.

\section{Follow-up}

Double-dose proton pump inhibitor treatment was given after the procedure and continued for two months.

Only patients with small lesions $(<1.5 \mathrm{~cm})$ in the gastric antrum were discharged in the first 4 to $6 \mathrm{hr}$. The others remained in the hospital for $24 \mathrm{hr}$.

Endoscopic control was done at 3, 6, 12 and 18 months after the procedure. In the absence of signs of residual or recurrent lesions after a period of 18 months, annual endoscopic control was indicated.

\section{RESULTS}

From the 20 patients included in the present study, 22 lesions were resected, including 16 gastric adenocarcinomas and 6 esophageal squamous carcinomas (Figure 1). The clinicopathological characteristics of the cases are shown in Table 3.

From the 15 patients with gastric lesions, we resected 16 lesions. No immediate or late complications, such as hemorrhage, perforation and stenosis, occurred in these cases. The only lesion with $\mathrm{Sm} 2$ invasion was referred for surgery. The two patients with $\mathrm{Sm} 1$ invasion did not present compromised margins; however, one patient had a focus of vascular invasion by the tumor. Clinical follow-up was opted for in this case, because the patient was diagnosed with sarcoma in the thigh with several pulmonary metastases. In the other patient with Sm1 invasion, surgery was indicated due to the undifferentiated nature of the lesion, and a residual lesion was not found in the surgical specimen.

Three lesions were not removed in the monoblock: one located in the cardia measuring $15 \mathrm{~mm}$, one in the posterior region of the antrum measuring $20 \mathrm{~mm}$, and the other in the angular incisure measuring $35 \mathrm{~mm}$ in its greatest axis.

Three lesions presented with compromised lateral margins. One lesion was complemented 30 days after ESD with EMR using the monofilament technique. The second was in a patient with an undifferentiated carcinoma with affected lateral and deep margins (Sm2); this patient was referred for surgical treatment after improvement of his
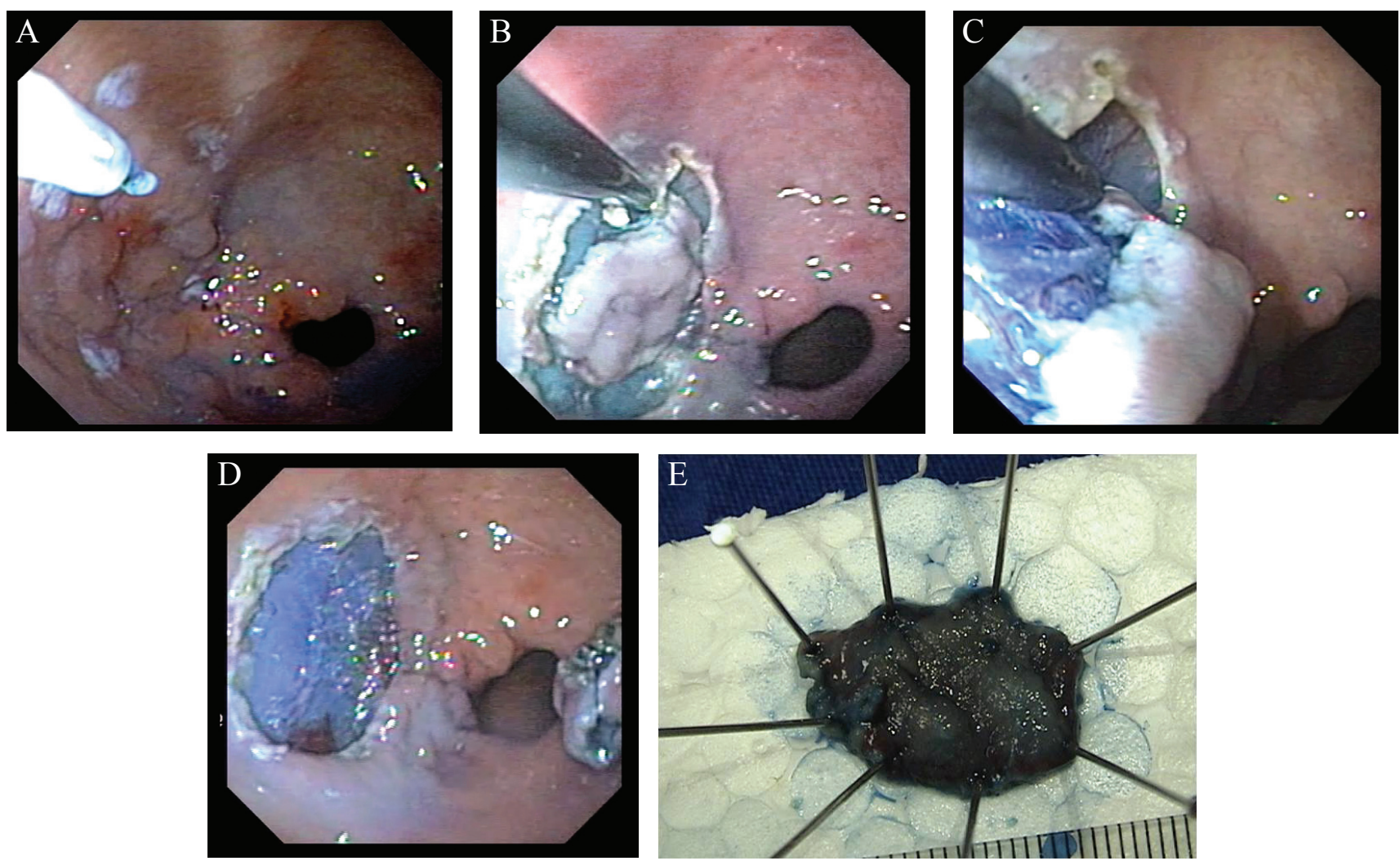

Figure 1 - Endoscopic submucosal dissection of a gastric adenocarcinoma (IIa+IIc). A- Marking of the lesion. B- Circumferential cutting around the entire lesion. C- Submucosal dissection of the lesion with the IT-knife. D- Complete resection of the lesion. E- ESD specimen (one piece). 
Table 3 - Clinicopathological characteristics.

\begin{tabular}{|c|c|c|}
\hline & $\begin{array}{l}\text { GASTRIC } \\
\text { LESIONS }\end{array}$ & $\begin{array}{l}\text { ESOPHAGEAL } \\
\text { LESIONS }\end{array}$ \\
\hline Patients/lesions & $15 / 16$ & $5 / 6$ \\
\hline Mean age (range) & $67.1(32-81)$ & $50.8(48-55)$ \\
\hline Male, n (\%) & $12(80 \%)$ & $4(80 \%)$ \\
\hline \multicolumn{3}{|l|}{ LOCATION, N } \\
\hline $\begin{array}{l}\text { Antrum, body, cardia, angular } \\
\text { incisure }\end{array}$ & $8,4,3,1$ & \\
\hline Middle, distal part & & 4,2 \\
\hline Lesion size, median (range), mm & $16.2(0.6-3.5)$ & $17.8(6-30)$ \\
\hline \multicolumn{3}{|l|}{ MACROSCOPIC TYPE, N } \\
\hline IIa + IIc, IIa, IIc, IIb, IIa & $8,4,4,0,0$ & $0,0,0,5,1$ \\
\hline $\begin{array}{l}\text { Procedure times, median (range), } \\
\text { min }\end{array}$ & $85(20-150)$ & $78(20-150)$ \\
\hline En-block resection, n (\%) & $13(81.2 \%)$ & $5(83.3 \%)$ \\
\hline \multicolumn{3}{|l|}{ DEPTH OF INVASION } \\
\hline $\mathrm{M} 1, \mathrm{M} 2, \mathrm{M} 3, \mathrm{Sm} 1, \mathrm{Sm} 2$ & $0,5,8,2,1$ & $3,1,1,1,0$ \\
\hline Lateral margins compromised, $\mathrm{n}(\%)$ & $3(18.7 \%)$ & 0 \\
\hline \multicolumn{3}{|l|}{ HISTOLOGIC TYPE , N (\%) } \\
\hline $\begin{array}{l}\text { Well-differentiated adenocarcinoma } \\
\text { Undifferentiated adenocarcinoma } \\
\text { Squamous cell carcinoma }\end{array}$ & $\begin{array}{c}13(81.2 \%) \\
3(18.7 \%) \\
0\end{array}$ & $\begin{array}{l}0 \\
0 \\
6\end{array}$ \\
\hline \multicolumn{3}{|l|}{ COMPLICATIONS, $\mathrm{N}$} \\
\hline $\begin{array}{l}\text { Immediate bleeding, later bleeding, } \\
\text { stenosis }\end{array}$ & $0,0,0$ & $0,0,0$ \\
\hline Perforations, pneumomediastinum & 0,0 & 0,2 \\
\hline Mortality & 0 & 0 \\
\hline
\end{tabular}

clinical condition of common variable immunodeficiency, where a focus of residual carcinoma was confirmed. For the third case with affected lateral margins, an endoscopic control was done 30 days after ESD. Several biopsy specimens were obtained from the resected border and determined to have no residual focus of carcinoma. Control follow-up was performed 90 days after resection, and the biopsies still did not have signs of residual lesion.

Excluding the two patients who underwent further surgery, the mean follow-up time was 9.5 months (2-24 months), with one patient dying from pneumonia seven months following the resection. One patient developed a new gastric metachronous adenocarcinoma after one year of follow-up, which was also resected using the ESD technique. The lesion was located next to the pylorus, and the resection of this lesion involved almost two-thirds of the circumference of the pyloric canal without progressing to stenosis.

From the five patients with esophageal squamous cell carcinoma, six lesions were removed. All patients were in treatment or follow-up of neck and head tumors. Two patients presented with pain and small pneumomediastinum; however, there was no evidence of perforation. Both cases had a good evolution with conservative treatment. Other complications, like bleeding and stenosis, did not happen. All had free lateral and deep margins. In four patients, the mean follow-up time was nine months (5-20 months) without residual or recurrent tumor. One patient was lost to follow-up.

\section{DISCUSSION}

The presence of lymph node metastasis is closely related to the degree of invasion into the esophageal and gastric wall.

Esophageal lesions confined to M1 and M2 layers do not present lymph node metastasis. As the lesion becomes deeper, the incidence of metastasis is: M3 (9.1\%), Sm1 (15.4\%), Sm2 (40.0\%), and Sm3 (44.1\%). ${ }^{5}$

According to the incidence of lymph node metastasis and local recurrence, Makuuchi ${ }^{5}$ defined the criteria for the endoscopic mucosal resection (EMR) of early esophageal lesions in 1996. The evolution of endoscopic resection methods has expanded the range of indications for endoscopic resections, but such procedures are formally not indicated in cases with $\mathrm{Sm} 2$ and $\mathrm{Sm} 3$ invasion detected on endoscopic ultrasound.

In the stomach, the incidence of lymph node metastasis for lesions confined to the mucosa and submucosa is generally considered to range from $0 \%$ to $3 \%$ and $9 \%$ to $19 \%$, respectively ${ }^{6}$.

An analysis of 1,312 gastrectomies for gastric cancer ${ }^{7}$ demonstrated a lymph node metastasis rate of $0.64 \%$ (3/462) for intestinal cancer confined to the mucosa, irrespective of the size of the lesion. The incidence of metastasis for undifferentiated lesions is rather high, even for lesions smaller in size.

In a study conducted at the National Cancer Center Hospital and the Cancer Institute Hospital in Tokyo ${ }^{8}$ on 3,016 intramucosal cancer lesions and 2,249 in the submucosa, the incidence of lymph node metastases was $2.2 \%$ for intramucosal cancers and $17.9 \%$ for the submucosal cancers. For the well-differentiated intramucosal cancers, none of the 929 lesions without ulceration were associated with nodal metastases regardless of the size of the lesion. Depressed or ulcerated lesions larger than 30 $\mathrm{mm}$ and with invasion into the lymphatic system or venules were associated with metastases. The overall risk of LN metastases in undifferentiated lesions was $4.2 \%$. However, none of the 141 intramucosal undifferentiated lesions without ulceration less than $20 \mathrm{~mm}$ in size showed lymph node metastases. For submucosal invasive cancer, 145 
lesions smaller than $30 \mathrm{~mm}$ that were well-differentiated, lacked lymphovascular invasion, and had submucosal penetration $<500 \mu \mathrm{m}(\mathrm{Sm} 1)$ were free of lymph node metastasis.

The technique of submucosal dissection using the IT-knife was the first technique of endoscopic mucosal dissection used in the National Cancer Center Hospital, Japan.9,10 Other ESD techniques were subsequently developed using different types of accessories, such as the hook-knife, the flex-knife, the triangle-tipped knife, and, more recently, the flush-knife and dual-knife.

In contrast to EMR techniques, ESD allows for large enbloc resections, contributing to better evaluation of resected specimens and consequently lower local recurrence of the neoplasia. In a previous series from our group, endoscopic mucosal resection (EMR) of gastric cancer in more than two fragments (piecemeal resection) was a risk factor for incomplete resection $(\mathrm{OR}=7.34)^{11}$. The incidence of local recurrence after EMR procedures ranges from $2.3 \%$ to $36.5 \%$, whereas for ESD it ranged from $0 \%$ to $2 \%$ in initial studies ${ }^{1}$. For en-bloc resection of gastric neoplasias, success rates for both techniques are similar and over $90 \%$ for lesions smaller than $1 \mathrm{~cm}$ in diameter. For lesions larger than $1 \mathrm{~cm}$, endoscopic submucosal dissection has a success rate of over $90 \%$, but for mucosectomies, this rate is decreased by half. ${ }^{12}$

The ESD procedure duration and incidence of complications are directly related to the experience of the endoscopist with this method.

The lesion that presented the most technical difficulty in this study was located in the cardia, where the procedure lasted 2 hours and $30 \mathrm{~min}$. Another difficult lesion was located in the angular incisure, where the procedure lasted
2 hours and $40 \mathrm{~min}$, with a lesion extension of $3.5 \mathrm{~cm}$. The lesions that presented the least technical difficulty were located in the antrum, particularly in the anterior distal region, where the procedure lasted only $20 \mathrm{~min}$.

The perforation incidence with different EMR techniques ranged from $0 \%$ to $4.0 \%$, whereas with ESD it ranged from $0 \%$ to $5.0 \%$. When comparing these methods, Watanabe and colleagues ${ }^{12}$ did not identify a statistical difference in the incidence of perforation, which was $3.2 \%$ for EMR and $4.2 \%$ for ESD. ${ }^{12}$ However, Oka and colleagues ${ }^{23}$ analyzed only non-ulcerative lesions and found a $0.5 \%$ incidence for EMR and a $9.7 \%$ incidence for EDS with statistical difference. Oda et al. ${ }^{13}$, in a multicenter retrospective study of early gastric cancer, observed the incidence of perforation with ESD $(3.6 \% ; 11 / 303)$ to be significantly higher than that with EMR (1.2\%; 5/411).

Bleeding is the most frequent complication for techniques of endoscopic resection. Its incidence for EMR was found to reach $8 \%$, whereas for ESD it reached $7 \%$. Oka and colleagues ${ }^{14}$ found that the incidence of bleeding during and after EMR was $7.6 \%$ and $3.9 \%$, respectively, for non-ulcerative lesions, whereas this incidence during and after ESD was $22.6 \%$ and $6.2 \%$, respectively. In a study by $\mathrm{Oda}^{13}$ et al., only one patient submitted to EMR required blood transfusion; no patients in the ESD group required transfusion.

Both perforation and bleeding are endoscopically treated with great success.

In the present study, there were no cases of perforation or other significant complications.

Given the present results and the data in the literature, we conclude that the ESD technique is feasible in our environment.

\section{REFERENCES}

1. Gotoda T. Endoscopic resections of early gastric cancer. Gastric Cancer. 2007;11:10-1.

2. Ciocirlan M, Lapalus MG, Hervieu V, Souquet J C, Napoléon B, Scoazec $\mathrm{JY}$, et al. Endoscopic mucosal resection for squamous premalignant and early malignant lesions of the esophagus. Endoscopy. 2007;39:24-9.

3. Higuchi K, Tanabe S, Koizumi W, Sasaki T, Nakatani K, Saigenji K, et al. Expansion of the indications for endoscopic mucosal resection in patients with superficial esophageal carcinoma. Endoscopy. 2007;39:3640.

4. Ishihara R, Iishi H, Takeuchi Y, Kato M, Yamamoto S, Masuda E, et al. Local recurrence of large squamous-cell carcinoma of the esophagus after endoscopic resection. Gastroint Endosc. 2008;67:799-804.
5. Makuuchi H. Endoscopic mucosal resection for early esophageal cancer: indications and techniques. Digestive Endoscopy 1996;8:175-9.

6. Kojima T, Parra-Blanco A, Takahashi H, Fujita R, et al. Outcome of endoscopic mucosal resection for early gastric cancer: review of the Japanese literature. Gastrointest Endosc. 1998;48:550-4.

7. Yoshida S. Endoscopic diagnosis and treatment of early cancer in the alimentary tract. Digestion. 1998;59:502-8.

8. Gotoda T, Yanagisawa A, Sasako M, Ono H, Nakanishi Y, Shimoda T, et al. Incidence of lymph node metastasis from early gastric cancer: estimation with a large number of cases at two large centers. Gastric Cancer. 2000;3:219-25. 
9. Hosokawa K, Yoshida S. Recent advances in endoscopic mucosal resection for early gastric cancer. Jpn J Cancer Chemother (in Japanese; abstract in English). 1998;25:483.

10. Gotoda T, Kondo H, Ono H, Saito Y, Yamaguchi H, Saito D, et al. A new endoscopic mucosal resection (EMR) procedure using an insulationtipped diathermic (IT) knife for rectal flat lesions. Gastrointest Endosc. 1999;50:560-3.

11. Hondo FY, Maluf-Filho F, Kishi HS, Uemura RS, Okawa L, Cecconello I, et al. Predicitive factors for local recurrence and incomplete resection of early gastric cancer treated by endoscopia resection: a Western experience. Can J Gastroenterol. 2009;23:357-63.
12. Watanabe K, Ogata S, Kawazoe S, Watanabe K, Koyama T, Kojiwara T, et al. Clinical outcomes of EMR for gastric tumors: historical pilot evaluation between endoscopic submucosal dissection and conventional mucosal resection. Gastrointest Endosc. 2006;63:776-82.

13. Oda I, Saito D, Tada M, Iishi H, Tanabe S, Oyama T, et al. A multicenter retrospective study of endoscopic resection for early gastric cancer. Gastric Cancer 2006;9: 262-70.

14. Oka S, Tanaka S, Kaneko I, Mouri R, Hirata M, Kawamura T, et al. Advantage of endoscopic submucosal dissection compared with EMR for early gastric cancer. Gastrointest Endosc. 2006;64:877-83. 